\title{
Economic and Environmental Assessment for Gas Supply Chains Incorporating Shale Gas
}

\section{Industrial and Engineering Chemistry Research}

\section{Supporting Information}

Josselin Colin-Robledo, ${ }^{a}$ Sergio Iván Martínez-Guido, ${ }^{a}$ Roberto GuerraGonzález, ${ }^{a}$ Luis Fernando Lira-Barragán, ${ }^{a^{*}}$ José María Ponce-Ortega, ${ }^{a}$

${ }^{a}$ Chemical Engineering Department, Universidad Michoacana de San Nicolás de Hidalgo, Morelia, Mich., 58060, México

* Corresponding author, $\underline{\text { 1flira@umich.mx }}$; Tel. +52 443 3223500; Fax. +52 4433273584

Content (9 pages, 3 tables and 2 figures).

This supporting information (9 pages) presents a set of tables (Tables S1 to S3) and figures (Figures S1 to S3) to show data for the addresses case study as well as the used nomenclature in the proposed optimization model. 


\section{Supplementary Material}

\section{S1. Case Study}

This example considers the hypothetic exploitation of the shale gas located in the Northeast of Mexico, specifically in Burgos basin. In this context, there are several challenges for the exploitation of shale gas in Mexico like the lack of infrastructure and some technical aspects found only in this region such as type of geology, gas composition, depth, physical properties, etc. Once that these concerns are overcome, other challenge appears, and it is referred to generate an optimal planning strategy to satisfy the overall gas requirements through a new gas supply chain incorporating the shale gas production. In this regard, in this case study the gas demands correspond to overall gas requirements in Mexico. Thus, the implementation of the proposed methodology aims to determine the optimal supply chain for the overall gas requirements in Mexico considering the production of shale gas, conventional gas and the imported gas under the current demands. It is important to mention that most of the information required to implement the proposed methodology in this case study has been taken from PEMEX (Mexican petroleum) reports as well as other data were taken from technical reports with updated data for the Marcellus and Barnett regions, ${ }^{\mathrm{S} 1, \mathrm{~S} 2}$ which are located in United States (the largest shale gas producer). In this sense, PEMEX considers five markets to distribute the gas to all the users according to Figure S1, even it is shown the potential locations for two hubs (owing to that zone corresponds to Burgos basin). ${ }^{\mathrm{S} 3}$

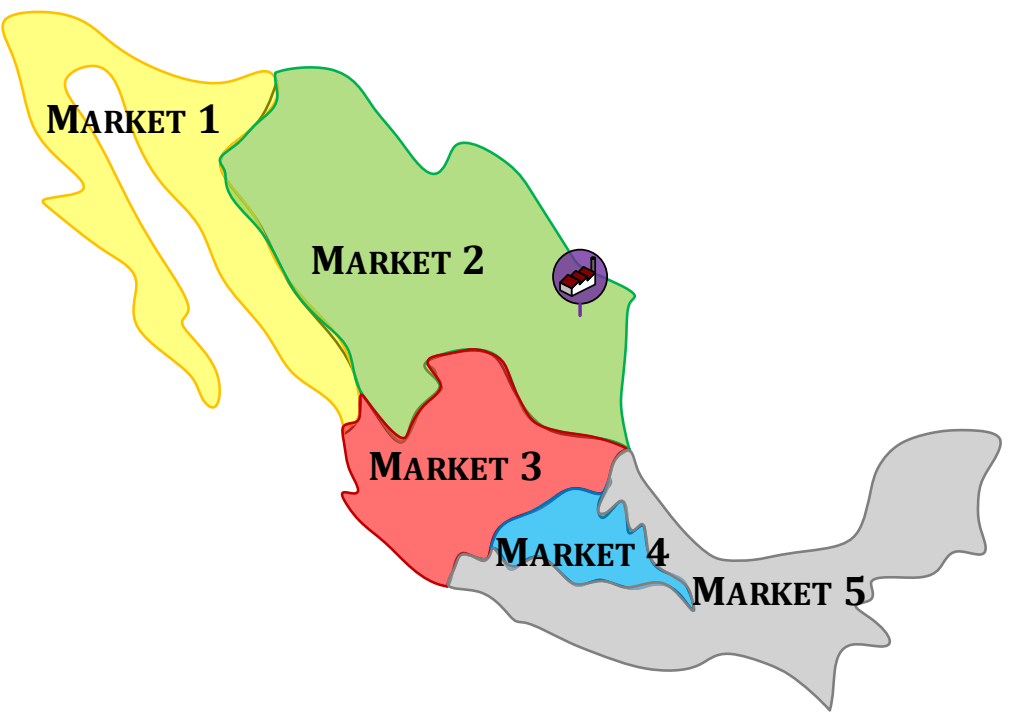

Figure S1. Distribution of markets and hubs in Mexico. 
As can be seen in Figure S2, it has been established the location for two hubs and there are considered 16 potential wells, which are grouped in four well pads. For each supply chain pathway, the environmental impact using the TRACI method was considered, ${ }^{\mathrm{S} 4}$ having that the impact categories with the higher values were global warming, eutrophication and human health. Notice that previous investigations are focused on measuring the environmental impact by the gas production, ${ }^{55-S 7}$ however in this paper are included the overall damage generated by all the steps in the gas network distribution by each option.

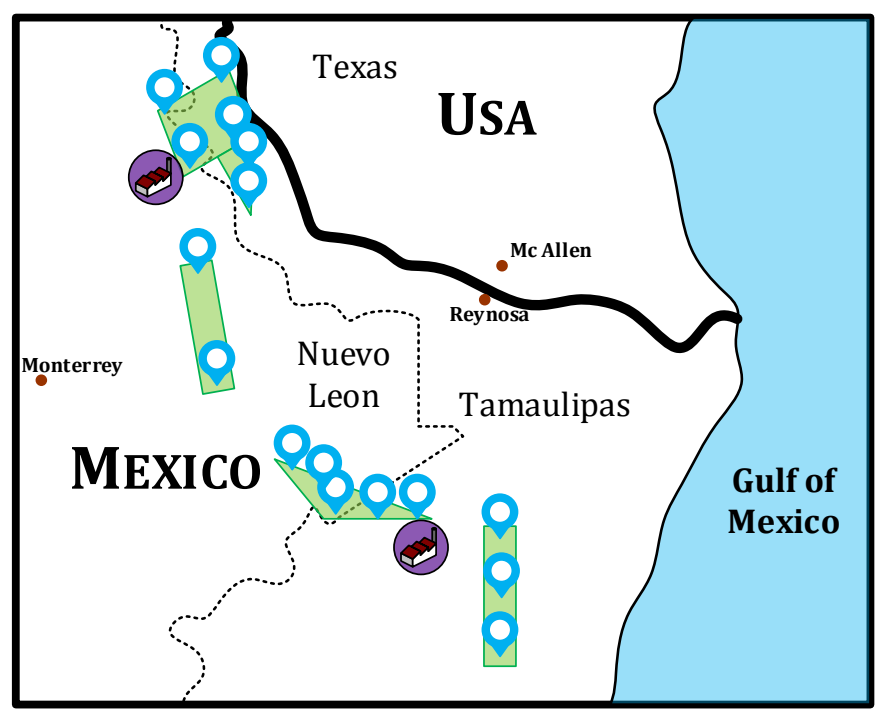

Figure S2. Location for pad wells and hubs in Burgos basin.

This example accounts for the following information:

- The gas selling prices in the markets $1-5$ are $0.392217,0.238869,0.289,0.277206$ and 0.318492 $\$ M M / M M S C F$, respectively (see Figure S1). ${ }^{\mathrm{S} 3}$

- Mexico has four main conventional gas zones and the total production of each region is 792.48 MMSCFD for all the months and the unit gain (i.e., the difference among the unit selling price and the unit production cost) is $0.12 \mathrm{SMM} / \mathrm{MMSCF}$. ${ }^{\mathrm{S} 3}$

- There are two sources to import additional gas, which correspond to gas coming from Peru and USA and the maximum availabilities in each time period are 8,076.85 MMSCFD and 104,109 MMSCFD, respectively. ${ }^{\mathrm{S} 8}$ Also, the unit gains (difference price - cost) for the gas imported from Peru and distributed in the markets $1-5$ are $1.219315 \times 10^{-2}, 7.208529 \times 10^{-3}, 8.838117 \times 10^{-3}, 8.454684 \times 10^{-3}$ and 9.796698 $\times 10^{-3}$ \$MM/ MMSCF; while unit gains for the gas imported from USA are presented in Table S1. 
- It is considered that water and $\mathrm{CO}_{2}$ are the fracturing fluids able to carry out the hydraulic fracturing process and their costs are $0.4 \$ \mathrm{MM} / \mathrm{m}^{3}$ and $0.083 \$ / \mathrm{m}^{3}$, respectively. ${ }^{\mathrm{S} 2}$ Notice that $\mathrm{CO}_{2}$ represents an important option to replace the relevant amounts of water used by hydraulic fracturing process. ${ }^{\mathrm{S9}, \mathrm{S} 10}$

- The fixed and variable charges for the installation of hubs are $0.066 \$ \mathrm{MM}$ and $2.142 \times 10^{-5} \$ \mathrm{MM} /$ MMSCF, respectively.

- The unit cost for fracturing process in well pads 1-4 are 5.76 $\times 10^{-4}, 1.92 \times 10^{-4}, 4.8 \times 10^{-4}$ and $2.88 \times 10^{-4}$ $\$ M M / M M S C F$, respectively. ${ }^{\mathrm{S} 1, \mathrm{~S} 2}$

- The unit transportation cost for well pads-hubs is $3.5 \times 10^{-4} \$ \mathrm{MM} / \mathrm{MMSCF} \mathrm{km}$; whereas the unit transportation cost from the hubs to markets $1-5$ are $37.579 \times 10^{-4}, 75.158 \times 10^{-4}, 75.158 \times 10^{-4}$, $112.736 \times 10^{-4}$ and $112.736 \times 10^{-4} \$ M M /$ MMSCF $\mathrm{km}$, respectively.

- The eco-indicators for the processing in hubs are $2.9724 \times 10^{-6}, 1.86982 \times 10^{-8}$ and $1.0464 \times 10^{-15}$ ton/MMSCF for global warming, eutrophication and human health, respectively.

- Besides, the overall unit eco-indicators (including extraction, transportation and processing) for global warming, eutrophication and human health with respect to the conventional gas are $3.4915337 \times 10^{-2}$, $3.85772 \times 10^{-6}$ and $1.05435 \times 10^{-12}$ ton/MMSCFD, respectively; whereas for imports of gas from USA are $4.7558908 \times 10^{-2}, 2.19567 \times 10^{-4}$ and $4.52367 \times 10^{-13}$ ton/MMSCFD, respectively and finally for imported gas from Peru are 2.23 for global warming and 7.89 $\times 10^{-3}$ ton/MMSCFD for eutrophication.

Table S1. Unit gains for the gas imported from USA.

\begin{tabular}{lccccc}
\hline \multirow{2}{*}{ Month/Market } & \multicolumn{5}{c}{ Unit gains for the gas imported from USA $(\$ M M / M M S C F)$} \\
\cline { 2 - 7 } January & $\mathbf{1}$ & $\mathbf{2}$ & $\mathbf{3}$ & $\mathbf{4}$ & $\mathbf{5}$ \\
February & 0.010549127 & 0.005564506 & 0.007194094 & 0.006810661 & 0.008152675 \\
March & 0.010869127 & 0.005884506 & 0.007514094 & 0.007130661 & 0.008472675 \\
April & 0.010869127 & 0.005884506 & 0.007514094 & 0.007130661 & 0.008472675 \\
May & 0.010719127 & 0.005734506 & 0.007364094 & 0.006980661 & 0.008322675 \\
June & 0.010689127 & 0.005704506 & 0.007334094 & 0.006950661 & 0.008292675 \\
July & 0.010289127 & 0.005304506 & 0.006934094 & 0.006550661 & 0.007892675 \\
August & 0.009949127 & 0.004964506 & 0.006594094 & 0.006210661 & 0.007552675 \\
September & 0.009829127 & 0.004844506 & 0.006474094 & 0.006090661 & 0.007432675 \\
October & 0.009689127 & 0.004704506 & 0.006334094 & 0.005950661 & 0.007292675 \\
November & 0.009589127 & 0.004604506 & 0.006234094 & 0.005850661 & 0.007192675 \\
December & 0.009999127 & 0.005014506 & 0.006644094 & 0.006260661 & 0.007602675 \\
\hline
\end{tabular}


Moreover, Table S2 shows the natural gas demands in each one of the five markets considered by this example and Table S3 contains the unit environmental impacts for the working fluids and for the transportation route well pads-hubs. It should be noted that the eco-indicators related to working fluids (i.e., for the hydraulic fracturing process) represent the highest values for unit environmental impacts with respect to the rest of unit eco-indicators, which will generate an important augment in the environmental impact for the possible solutions where shale gas is required comparing with the optimal solutions where shale gas does not appear. Also notice that, for most of the cases, the eco-indicators for $\mathrm{CO}_{2}$ are higher than water. Although, $\mathrm{CO}_{2}$ sequestration is a potential source to obtain this fluid and considering that this process involves significant environmental benefits, the augment in eco-indicators when $\mathrm{CO}_{2}$ is employed as fracturing fluid is generated by the compression process for $\mathrm{CO}_{2}$ owing to the compression requirements are greater with respect to water and it is necessary to achieve higher pressures. Also, for the transportation of the fluids, the water pumping represents a lower impact with respect to $\mathrm{CO}_{2}$ compression. Thus, the ecological footprint for compression process is capable to revert the benefits owing to $\mathrm{CO}_{2}$ sequestration. However, this does not mean that the incorporation of $\mathrm{CO}_{2}$ as working fluid is not relevant, in the most of the shale plays the main technical problem is related to the water availability and $\mathrm{CO}_{2}$ offers an alternative to overcome this drawback.

Table S2. Natural gas demands in the markets.

\begin{tabular}{lccccc}
\hline \multirow{2}{*}{ Month/Market } & \multicolumn{5}{c}{ Natural gas demands in the markets } \\
\cline { 2 - 6 } & $\mathbf{1}$ & $\mathbf{2}$ & $\mathbf{3}$ & $\mathbf{4}$ & $\mathbf{5}$ \\
\hline January & 533.41 & 1848.567 & 845.701 & 760.654 & 2173.784 \\
February & 529.922 & 1836.476 & 840.169 & 755.679 & 2159.566 \\
March & 521.934 & 1808.795 & 827.505 & 744.289 & 2127.015 \\
April & 512.502 & 1776.108 & 812.551 & 730.839 & 2088.577 \\
May & 505.641 & 1752.33 & 801.673 & 721.054 & 2060.616 \\
June & 509.036 & 1764.094 & 807.055 & 725.895 & 2074.45 \\
July & 500.769 & 1735.445 & 793.948 & 714.106 & 2040.76 \\
August & 492.158 & 1705.605 & 780.297 & 701.828 & 2005.671
\end{tabular}




\begin{tabular}{lccccc} 
September & 486.396 & 1685.636 & 771.161 & 693.611 & 1982.189 \\
October & 483.25 & 1674.731 & 766.173 & 689.124 & 1969.365 \\
November & 477.395 & 1654.443 & 756.891 & 680.775 & 1945.507 \\
December & 465.738 & 1614.042 & 738.408 & 664.151 & 1898 \\
\hline
\end{tabular}

Table S3. Unit environmental impacts in ton/MMSCFD.

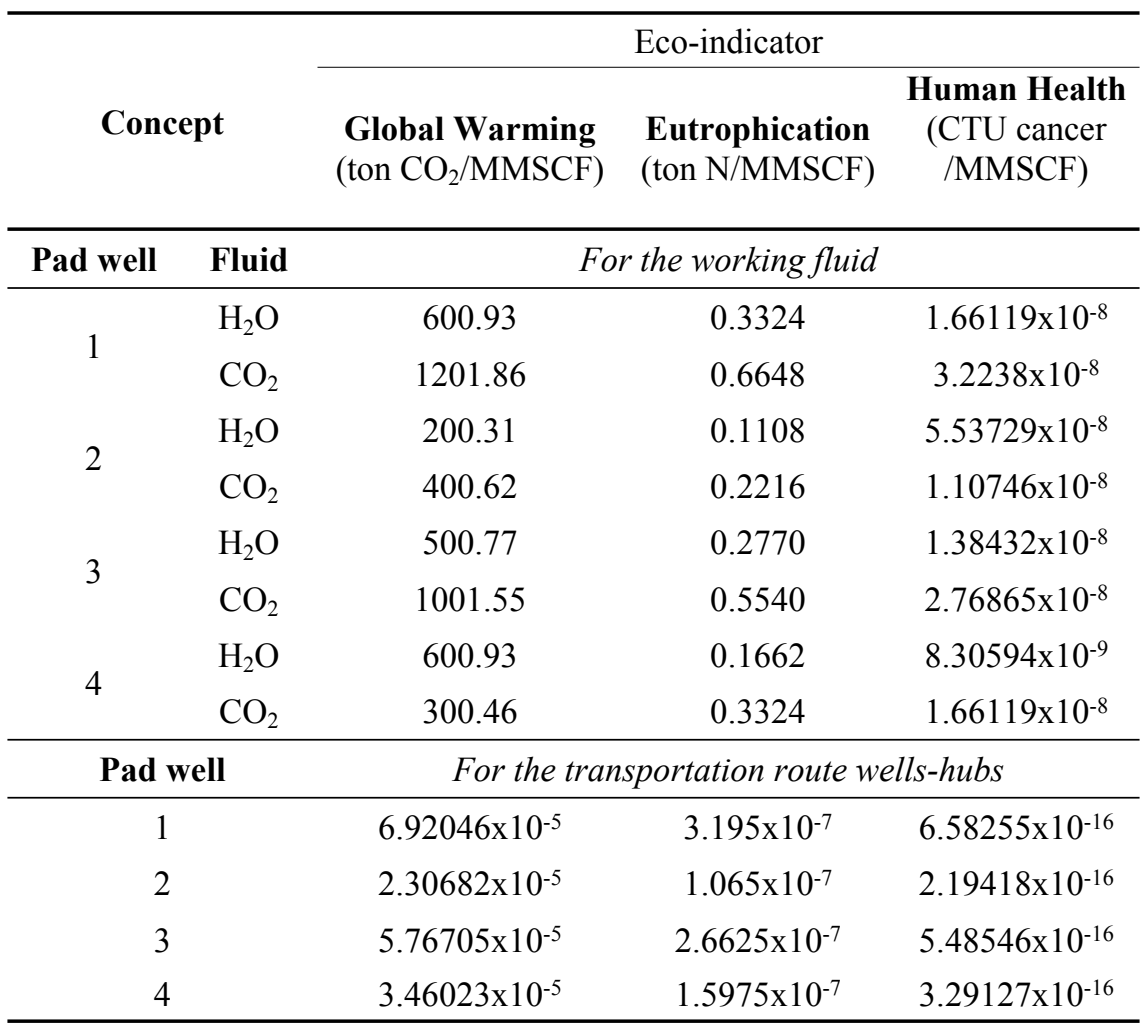

\section{S2. Nomenclature}

\section{Parameters}

$D_{t} \quad$ time conversion factor, $\mathrm{d} /$ month

$F_{h}^{\max -c a p-h u b} \quad$ maximum capacity for the hub $h$, MMSCFD

$F_{i, t}^{\max -\text { well }} \quad$ maximum capacity for the shale gas available at the well $i$ in the time $t$, MMSCFD

$F_{p, t}^{\max -c o n v} \quad$ maximum availability for the conventional gas at the site $p$ in the time $t$, MMSCFD

$F_{e, t}^{\max -i m p o r t} \quad$ maximum availability for the importing gas in the source $e$ in the time $t$, MMSCFD 
$F_{j, t}^{\text {Gas-Market }}$

$F C_{h}^{h u b}$

$k_{F}$

$M^{\operatorname{Cos} t^{f l u i d}}$

$M^{E I^{\text {fluid }}}$

NPV

$O U E I_{p, j}^{c o n v}$

OUEI $I_{e, j}^{\text {import }}$

$U C_{i, f, t}^{\text {fuid }}$

$U C_{i, t}^{\text {fracking }}$

$U C_{h, t}^{\text {process }}$

$U C_{i, h}^{\text {trans-well-hub }}$

$U C_{h, j}^{\text {trans-hub-market }}$

$U E I_{i, f}^{\text {fluid }}$

$U E I_{h}^{\text {process }}$

$U E I_{i, h}^{\text {trans-well-hub }}$

$U E I_{h, j}^{\text {trans-hub-market }}$

$U P_{h, j, t}^{g a s}$

$U P C_{p, j, t}^{c o n v}$

$U P C_{e, j, t}^{\text {import }}$

$V C_{h}^{h u b}$

\section{Greek Symbols}

$\alpha^{h u b}$ natural gas demands at the market $j$ in the time $t$, MMSCFD

fixed charge for the hub plant in the capital cost function, \$MM

factor used to annualize the investment, $\mathrm{y}^{-1}$

maximum value for the working fluid cost, \$MM

maximum value for the environmental impact of the working fluid, \$MM

value at present time, $\$ M M$

overall unit environmental impact for the conventional gas, environmental unit/

MMSCF

overall unit environmental impact for the imported gas, environmental unit/

MMSCF

unit cost for the working fluid $f$, \$MM/ MMSCF

unit cost for the fracturing in the well $i, \$ \mathrm{MM} / \mathrm{MMSCF}$

unit cost for the shale gas processing at hub $h, \$ \mathrm{MM} / \mathrm{MMSCF}$

unit transportation cost from the well $i$ to the hub $h, \$ M M / M M S C F$

unit transportation cost from the hub $h$ to the market $j, \$ M M / M M S C F$

unit environmental impact for the working fluid, environmental unit/ MMSCF

unit environmental impact for the processing, environmental unit/ MMSCF

unit environmental impact for the transportation from wells to hubs, environmental unit/ MMSCF

unit environmental impact for the transportation from hubs to markets, environmental unit/MMSCF

unit price for the natural gas, \$MM/ MMSCF

unit difference among price and cost for conventional gas, \$MM/ MMSCF

unit difference among price and cost for imported gas, \$MM/ MMSCF

variable charge for the hub plant in the capital cost function, \$MM/ MMSCF

exponent for the economies of scale 
$\alpha_{h}^{\text {proces-rawgas }}$

\section{Variables}

Cap Cos $t^{\text {hubs }}$

$\operatorname{Cos} t_{i, f}^{\text {fluid-fracking }}$

$\operatorname{Cos} t^{\text {fracking }}$

$\operatorname{Cos} t^{\text {processing }}$

Cost $t^{\text {trans-hub-market }}$

$\operatorname{Cos} t^{\text {trans-well-hub }}$

$E I^{\text {conv-gas }}$

$E I_{i, f}^{\text {fluid - fracking }}$

EI $I^{\text {import-gas }}$

$E I^{\text {processing }}$

$E I^{\text {shale-gas }}$

EI $I^{\text {trans-well-hub }}$

EI $I^{\text {trans-hub-market }}$

$F_{h}^{c a p-h u b}$

$F_{p, t}^{\text {conventional }}$

$F_{h, t}^{h u b-i n}$

$F_{h, t}^{h u b-o u t}$

$F_{e, t}^{\text {imported }}$

$F_{i, t}^{\text {well }}$

$f_{p, j, t}^{c o n v-m a r k e t}$

$f_{h, j, t}^{h u b-m a r k e t}$

$f_{e, j, t}^{\text {import-market }}$

$f_{i, h, t}^{w e l l-h u b}$

Profit ${ }^{\text {conv-gas }}$ volumetric efficiency for the processing plants

capital cost for the hubs, \$MM

fracturing fluid cost, \$MM

hydraulic fracturing cost, \$MM

shale gas processing cost, \$MM

total transportation cost from hubs to markets, \$MM

total transportation cost from wells to hubs, \$MM

overall environmental impact generated by conventional gas, environmental unit environmental impact generated by the fracturing fluid, environmental unit

overall environmental impact generated by the imported gas, environmental unit environmental impact for the shale gas processing, environmental unit overall environmental impact generated by the shale gas, environmental unit environmental impact for the transportation from wells to hubs, environmental unit environmental impact for the transportation from hubs to markets, environmental unit

capacity flowrate for hub $h$, MMSCFD

conventional gas production in the site $p$ in the time $t$, MMSCFD

gas flowrate entering the hub $h$ in the time $t$, MMSCFD

gas flowrate leaving the hub $h$ in the time $t$, MMSCFD

imported gas flowrate from the source $e$ in the time $t$, MMSCFD

shale gas production in the well $i$ in the time $t$, MMSCFD

gas flowrate sent from the conventional site $p$ to market $j$ in the time $t$, MMSCFD

gas flowrate sent from the hub $h$ to the market $j$ during the time period $t$, MMSCFD

gas flowrate sent from the importing source $e$ to market $j$ in the time $t$, MMSCFD

gas flowrate sent from the well $i$ to the hub $h$ in the time $t$, MMSCFD

conventional gas profits, \$MM 


$\begin{array}{ll}\text { Profit }^{\text {import-gas }} & \text { imported gas profits, \$MM } \\ \text { Profit }^{\text {shale-gas }} & \text { shale gas profits, \$MM } \\ \text { Sales }^{\text {shale-gas }} & \text { shale gas incomes, \$MM } \\ \text { TEI } & \text { overall environmental impact generated by the project, environmental unit } \\ T P P & \text { total profits, \$MM } \\ y_{i, f}^{\text {fluid-fracking }} & \text { binary variable used to select the fracturing fluid } f \text { in the well } i \\ y_{h}^{\text {hub }} & \text { binary variable used to model the existence of the hub } h\end{array}$

Sets

$E \quad\{e \mid e$ is a gas importing source $\}$

$F \quad\{f \mid f$ is a fracturing fluid $\}$

$H \quad\{d \mid d$ is a hub/processing plant $\}$

I $\quad\{i \mid i$ is a pad well $\}$

$J \quad\{j \mid j$ is a market $\}$

$P \quad\{p \mid p$ is a conventional gas production site $\}$

$T \quad\{t \mid t$ is a time period $\}$

Subscripts and Superscripts

e gas importing source

$f \quad$ fracturing fluid

$h \quad$ hub/processing plant

i well pad

jarket

p conventional gas production site

$t \quad$ time period

\section{References}

(S1) Slutz, J., Anderson, J, Broderick, R., \& Horner, P. (2012). Key Shael Gas water management strategies: an economic assessment tool. SPE/APPEA International Conference on Health, Safety and Environment in Oil and Gas Exploration an Production. 
(S2) Hayes, T. (2009). Sampling and analysis of water streams associated with the development of Marcellus shale gas. Marcellus Shale Initiative Publications Database,10 http://energyindepth.org/wp-content/uploads/marcellus/2012/11/MSCommission-Report.pdf (Accessed March 2019).

(S3) SENER. (2016). Prospectiva de Gas Natural 2016-2030. México. gob.mx/cms/uploads/attachment/file/177624/Prospectiva_de_Gas_Natural_2016-2030.pdf (accessed March 2019).

(S4) Bare, J. C. (2002). TRACI: The tool for the reduction and assessment of chemical and other environmental impacts. $J$ Ind Ecol, 6(3-4), 49-78.

(S5) Zeng, S., Gu, j., Yang, S., Zhou, H., Qian, Y. (2019) Comparison of techno-economic performance and environmental impacts between shale gas and coal-based synthetic natural gas (SNG) in China. J Clean Prod, 215, 544-556.

(S6) Grecu, E., Aceleanu, M. I., \& Albulescu, C. T. (2018) The economic, social and environmental impact of shale gas exploitation in Romania: A cost-benefit analysis. Renew Sust Energ Rev, 93, 691700 .

(S7) Guo, M., Xu, Y., \& Chen, Y. D. (2019) Environmental enforcement and compliance in Pennsylvania’s Marcellus shale gas development. Resour Conserv Recy, 144, 24-31.

$$
\text { Perupetro. }
$$

Perú

petro.

Obtenido

de https://www.perupetro.com.pe/wps/portal/corporativo/PerupetroSite/!ut/p/z1/04_Sj9CPykssy0xPL MnMz0vMAfIjo8zi_YxcTTw8TAy9_B1dLA0czY28_QID_Q1c_Qz0w8EKDHAARwP9KGL041 EQhd_4cP0oQkoKckMjDNIVFQHyd0I7/dz/d5/L2dBISEvZ0FBIS9nQSEh (Accessed March 2019).

(S9) Wu, X., Zhang, Y., Sun, X., Huang, Y., Dai, C., \& Zhao, M. (2018). A novel CO2 and pressure responsive viscoelastic surfactant fluid for fracturing. Fuel, 229, 79-87.

(S10) Li, X., Ventura, J. A., \& Ayala, L. F. (2018). Carbon dioxide source selection and supply planning for fracking operations in shale gas and oil wells. J Nat Gas Sci Eng, 55, 74-88. 